\title{
Results of screening first-degree relatives of patients with colorectal cancer: A community practice perspective
}

David J Beaudin MDCM FRCPC

DJ Beaudin. Results of screening first-degree relatives of patients with colorectal cancer: A community practice perspective. Can J Gastroenterol 2000;14(6):489-492. Targeted screening by colonoscopy of asymptomatic first-degree relatives of patients with colorectal cancer (CRC) is promoted as a preventive health activity. This retrospective case control series details the results of this activity in a community-based referral gastroenterology practice. One advanced carcinoma and 22 adenomas in $15 \mathrm{pa}-$ tients were found in 118 individuals screened. Six per cent of those screened had advanced lesions (carcinoma, tubulovillous adenomas or adenomas larger than $1 \mathrm{~cm}$ ). Colonoscopic screening of asymptomatic first-degree relatives of patients with CRC yields a limited number of clinically significant colonic neoplasms in this practice setting. Further cost-benefit data are needed.

Key Words: Colonoscopy; Colorectal adenomas; Colorectal cancer; Screening

\section{Résultats d'un dépistage auprès des parents proches de patients atteints d'un cancer rectocolique : Point de vue de la pratique communautairee}

\begin{abstract}
RÉSUMÉ : Cet article fait la promotion de la colonoscopie de dépistage ciblée auprès des parents proches asymptomatiques de patients atteints d'un cancer rectocolique comme mesure préventive. Cette série rétrospective de cas témoins présente les résultats de ce type d'intervention dans une pratique de gastro-entérologie communautaire. Un cancer avancé et 22 adénomes ont ainsi été dépistés chez 15 patients après des tests effectués chez 118 individus. Six pour cent des sujets qui ont subi les tests de dépistage étaient porteurs de lésions avancées (carcinomes, adénomes tubulovilleux ou adénomes de plus de $1 \mathrm{~cm}$ ). L'examen colonoscopique des parents proches asymptomatiques de patients atteints de cancer rectocolique a permis de mettre au jour un nombre limité de néoplasies cliniquement significatives du côlon dans cette pratique. Il reste encore à déterminer le rapport coût-bénéfices de ce type d'intervention.
\end{abstract}

$\mathrm{C}$ olorectal cancer (CRC) is a cause of major morbidity and mortality in industrialized countries, where it occurs in approximately $5 \%$ of the population, resulting in a near $50 \%$ mortality. It is thought that most CRCs develop in pre-existing benign adenomas and that the sequence from adenoma to invasive malignancy takes approximately 10 years. A large scale, prospective study of patients whose adenomas had been removed demonstrated a decreased mortality from colorectal cancer (1). Screening for colonic adenomas and presymptomatic invasive cancer is, therefore, widely promoted as a preventive health activity $(2,3)$. There is undoubtedly a benefit in high risk populations with he-

Saint John Regional Hospital, Saint John, New Brunswick

Correspondence and reprints: Dr David J Beaudin, 707 Millidge Avenue, Saint John, New Brunswick E2K 2N7. Telephone 506-648-7930, fax 506-648-6813, e-mail beaudind@nbnet.nb.ca

Received for publication July 15, 1999. Accepted July 16, 1999 
TABLE 1

Characteristics of 118 individuals screened

\begin{tabular}{|c|c|c|c|}
\hline & $\begin{array}{l}\text { All screened } \\
\text { n (\%) }\end{array}$ & $\begin{array}{c}\text { No neoplasm } \\
n(\%)\end{array}$ & $\begin{array}{l}\text { Neoplasm } \\
\text { n (\%) }\end{array}$ \\
\hline Total & 118 & $102(86)$ & $16(14)$ \\
\hline Female & $79(67)$ & 69 & 10 \\
\hline Male & $39(33)$ & 33 & 6 \\
\hline $\begin{array}{l}\text { Average age at } \\
\text { colonoscopy, } \\
\text { years (range) }\end{array}$ & $54(34-77)$ & $53(34-76)$ & $61(42-77)$ \\
\hline $\begin{array}{l}\text { Number with one } \\
\text { affected relative }\end{array}$ & $94(80)$ & $80(78)$ & $14(87)$ \\
\hline $\begin{array}{l}\text { Number with two } \\
\text { affected relatives }\end{array}$ & $18(15)$ & $17(17)$ & $1(6)$ \\
\hline $\begin{array}{l}\text { Number with three } \\
\text { affected relatives }\end{array}$ & $6(5)$ & $5(5)$ & $1(6)$ \\
\hline $\begin{array}{l}\text { Number with one } \\
\text { affected parent }\end{array}$ & 64 & 54 & 10 \\
\hline $\begin{array}{l}\text { Number with both } \\
\text { parents affected }\end{array}$ & 5 & 5 & 0 \\
\hline $\begin{array}{l}\text { Number with one } \\
\text { affected sibling }\end{array}$ & 30 & 26 & 4 \\
\hline $\begin{array}{l}\text { Number with other } \\
\text { combinations }\end{array}$ & 19 & 18 & 1 \\
\hline $\begin{array}{l}\text { Number with relative age } \\
50 \text { years or younger at } \\
\text { diagnosis }\end{array}$ & 38 & 36 & 2 \\
\hline
\end{tabular}

reditary colon cancer (familial adenomatous polyposis [FAP] and Lynch syndromes). There are limited scientific data supporting this activity in average risk populations. Many studies have reported that individuals who have one or more first-degree relatives with CRC have a two- to threefold increased risk of CRC and a high prevalence of colonic adenomas $(4,5)$. Therefore, there may be a cost-benefit for targeted screening if it can be demonstrated that asymptomatic pathology can be consistently identified more frequently than in the general population $(6,7)$. It is generally accepted that colonoscopy is the most sensitive and specific method of screening for CRC. This communication describes the results of such targeted screening in a private gastroenterology referral practice in New Brunswick over a 10-year period.

\section{PATIENTS AND METHODS}

The records of all patients, referred or identified with a family history of CRC in first-degree relatives who subsequently had colonoscopy, were screened for inclusion. By using an electronic database, records of potentially eligible patients were flagged at the time of initial clinical assessment. Individuals with a personal history of colonic polyps, an abnormal barium enema or colonic symptoms (except minor wipe bleeding) were excluded. A family history of FAP or one fulfilling the Amsterdam criteria for Lynch syndrome was an exclusion criterion. In many instances, no independent documentation of the family history was obtained.
TABLE 2

Characteristics of 22 neoplastic polyps

\begin{tabular}{lcccc}
\hline Histology & Total & $\begin{array}{c}\mathbf{1} \mathbf{~ c m} \text { or } \\
\text { larger }\end{array}$ & $\begin{array}{c}\text { Average } \\
\text { size }(\mathbf{c m})\end{array}$ & Range $(\mathbf{c m})$ \\
\hline Tubular adenoma & 16 & 0 & 0.4 & $0.2-0.8$ \\
Tubulovillous & 6 & 2 & 0.9 & $0.3-2.0$ \\
\hline
\end{tabular}

Twenty-three cases initially flagged were subsequently excluded on the basis of these criteria. The final cohort was, therefore, highly selected, comprising only those whose sole indication for colonoscopy was their family history.

All colonoscopies were performed using conscious sedation by the author in the gastrointestinal laboratory of the Saint John Regional Hospital, Saint John, New Brunswick. Olympus fibrecolonoscopes, and in the past two years, videocolonoscopes, were used for the examinations. Preparation was with magnesium sulphate solution in the early years and with sodium sulphate solution in the last five years of the study. Each examination was graded for adequacy of preparation and completeness. An excellent preparation was defined as one in which only easily aspirated clear or translucent fluid remained in the colon. A satisfactory preparation was defined by the presence of nonsolid stool that could be aspirated. Identification of the ileocecal valve and/or appendiceal orifice was used to indicate complete colonoscopy. All lesions $3 \mathrm{~mm}$ or greater were removed with cold or hot biopsy forceps or with electrosurgical snare. All specimens were processed by routine methodology in the hospital histopathology laboratory and reported according to current criteria. Polyps reported as purely hyperplastic were considered non-neoplastic.

\section{RESULTS}

One hundred and eighteen individuals fulfilling the above criteria were examined during the 10 years of the study -25 patients since 1997. Ninety-six per cent (113 of 118) of the colonoscopies were complete. Preparation was deemed excellent or satisfactory $92 \%$ of the time. For further analysis, 118 patients were placed into one of two groups - those with neoplasm and those without neoplasm (Table 1). The group with neoplasms tended to be older than those without. The groups were not different in terms of numbers of relatives with CRC. Contrary to expectation, a higher proportion of those negative for neoplasm had young relatives affected by CRC than did those found to have neoplasms at colonoscopy.

One 59-year-old man was found to have a hepatic flexure carcinoma. He died two years later of metastatic disease despite prompt resection followed by chemotherapy. Fifteen other patients were found to have 22 neoplastic polyps ( $\mathrm{Ta}$ ble 2), seven of which were pedunculated. Two polyps, in different patients, were $1 \mathrm{~cm}$ or larger, and both had tubulovillous histology. Two patients had three adenomas each, the largest of which was $0.8 \mathrm{~cm}$. All others had one each.

Five patients with adenomas have had nine follow-up colonoscopies. Three patients were found to have developed 
additional adenomas. One patient had adenomas of 1.5 and $1.2 \mathrm{~cm}$ with tubulovillous histology at two subsequent examinations. The five adenomas removed from four other patients were all smaller than $1.0 \mathrm{~cm}$.

The ages at diagnosis of 134 affected first-degree relatives were known. These data are included in Table 3 for various categories of individuals screened. Twenty-eight per cent of first-degree relatives with CRC were aged 50 years or younger at diagnosis.

\section{DISCUSSION}

Although colonoscopic screening of the general population is strongly promoted by various interest groups on the basis of extrapolation from population studies and computer modelling, there is scant evidence of clinical efficacy, let alone cost efficacy. First-degree relatives of patients with CRC have long been considered at increased risk, and there is considerable evidence supporting this belief. The reported prevalence of adenomas and cancers has varied widely in firstdegree relatives screened by colonoscopy, even in studies from populations who are expected to have similar prevalence. These divergent data may be explained by the small case numbers in some studies, inclusion of symptomatic individuals among those 'screened' and the classification of hyperplastic polyps as neoplastic. Local population and geographic variations in the incidence of $\mathrm{CRC}$ seem to be unlikely factors.

This report derived from a clinical practice in a nonacademic setting shows a $14 \%$ prevalence of neoplasm. Twenty-eight per cent of the study population had firstdegree relative(s) who were aged 50 years or younger at diagnosis. This risk factor has been reported to be associated with an increased yield of advanced lesions (8) but was not identified as a risk factor in this study. A similar study was reported in 1990 by Brzezinski et al (9) from Alberta. They found a more than $25 \%$ prevalence of polyps (56\% if two or more first-degree relatives had CRC) but included hyperplastic as well as adenomatous polyps in part of their study. The present study found one patient with carcinoma, no tubular adenomas larger than $1 \mathrm{~cm}$ and six tubulovillous adenomas that is, six patients $(5 \%)$ would be considered to have high grade lesions by current criteria. These findings are similar to those reported by Luchtefeld et al (10) from Michigan in 1991 in a controlled study of 160 asymptomatic first-degree relatives.

The yield of screening colonoscopy in those with a family history of CRC has been reported to vary from $11 \%$ to more than $60 \%$ (11). A number of factors may account for the discrepancies among these reports, which for the most part deal with small populations. Referral bias favours health conscious patients, who tend to present at a young age with minimal criteria, ie, one elderly first-degree relative with CRC. This does not seem to have been a factor in the present report. Ensuring that symptomatic individuals have been excluded is very difficult in retrospective studies. This may well account for the high prevalence of neoplastic lesions in some reports. Studies based on large populations
TABLE 3

Ages of 134 relatives with colorectal cancer

\begin{tabular}{lcccc}
\hline & Number & $\begin{array}{c}\text { Average age } \\
\text { (years) }\end{array}$ & $\begin{array}{c}\text { Age range } \\
\text { (years) }\end{array}$ & $\begin{array}{c}\text { Number aged 50 } \\
\text { years or younger }\end{array}$ \\
\hline Fathers & 38 & 61 & $28-92$ & 7 \\
Mothers & 49 & 61 & $32-88$ & 14 \\
Brothers & 14 & 55 & $42-70$ & 5 \\
Sisters & 33 & 54 & $31-73$ & 12 \\
\hline
\end{tabular}

(12) clearly show that family history is an important risk factor for CRC. A recent case control study (13) from France confirms the increased prevalence of high risk adenomas in individuals with a positive family history. Nonetheless, a number of reports including this one show a limited yield of adenomas in those whose only indication for examination is the positive family history. In some series, men are more often found to harbour advanced lesions than women (5). The present report contains a high proportion of women. Finally, in the present report, greater numbers of first-degree relatives with CRC did not distinguish the group with neoplasms from the group without neoplasms.

\section{CONCLUSIONS}

In recent years, patients have commonly been referred for colonoscopic screening because of a family history of CRC. Because colonoscopy is unpleasant and carries some morbidity and/or mortality, it is appropriate to discuss the risks, benefits and potential yield of this examination with such patients and allow the patient to make an informed decision about whether to accept screening and by what modality. Nonetheless, this study should in no way alter the practice of recommending early and aggressive investigation of colonic symptoms in patients of an appropriate age with a positive family history of CRC.

ACKNOWLEDGEMENTS: This article is dedicated to Dr IT Beck. This is the paper that I promised you in 1971! I also thank Dr Eric Grant for his review of this manuscript and many helpful suggestions.

\section{REFERENCES}

1. Winawer SJ, Zauber AG, Ho MN, et al. Prevention of colorectal cancer by colonoscopic polypectomy. N Engl J Med 1993;329:197781.

2. Winawer SJ, St John DJ, Bond JH, et al. Prevention of colorectal cancer: guidelines based on new data. Bull World Health Organ 1995;73:7-10

3. Levin B, Bond JH. Colorectal cancer screening: recommendations of the the U. S. Preventive Services Task Force. Gastroenterology 1996;111:1381-4.

4. Burt RW. Colonoscopic surveillance for the patient with a family history of colorectal cancer. Gastrointest Endosc Clin North Am 1993;3:715-24.

5. Guillem JG, Forde KA, Treat MR, et al. Colonoscopic screening for neoplasm in asymptomatic first-degree relatives of colon cancer patients. Dis Colon Rectum 1992;35:523-96.

6. Johnson DA, Gumey MS, Volpe RJ, et al. A prospective study of the 
prevalence of colonic neoplasms in asymptomatic patients with an age-related risk. Am J Gastroenterol 1990;85:969-74.

7. Disario JA, Foutch PG, Mai HD, et al. Prevalence and malignant potential of colorectal polyps in asymptomatic, average risk men. Am J Gastroenterol 1991;86:941-5.

8. Aitken JF, Bain CJ, Ward M. Risk of colorectal adenomas in patients with a family history of colorectal cancer: some implications for screening programmes. Gut 1996;39:105-89.

9. Brzezinski W, Orrom WJ, Wiens E. Prospective and retrospective analysis of colonoscopy findings in patients with a history of colorectal carcinoma in first-degree relatives. Can J Surg 1990;33:314-6.
10. Luchtefeld MA, Syverson D, Solfelt M. Is colonoscopic screening appropriate in asymptomatic patients with family history of colon cancer? Dis Colon Rectum 1991;34:763-8

11. Rex DK. Colonoscopy: a review of its yield for cancers and adenomas by indication. Am J Gastroenterol 1995;90:353-65.

12. Fuchs CS, Giovannucci EL, Colditz GA, et al. A prospective study of family history and the risk of colorectal cancer. N Engl J Med 1994;331:1669-74.

13. Pariente A, Milan C, Lafon J, et al. Colonoscopic screening in firstdegree relatives of patients with 'sporadic' colorectal cancer: a casecontrol study. Gastroenterology 1998;115:7-11. 


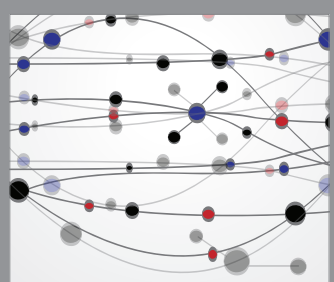

The Scientific World Journal
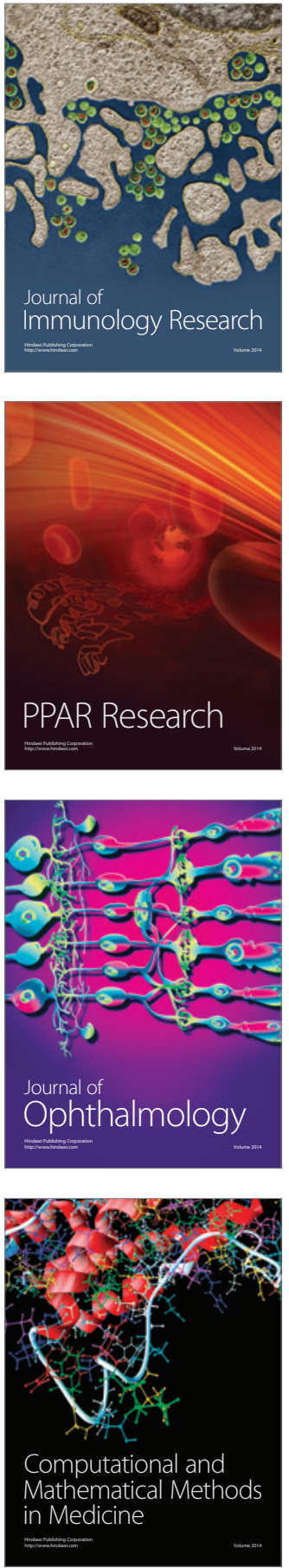

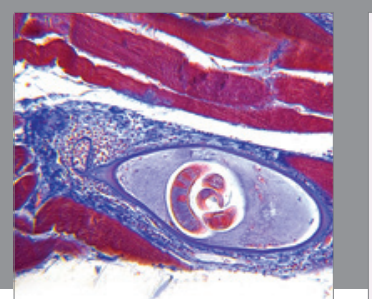

Gastroenterology Research and Practice

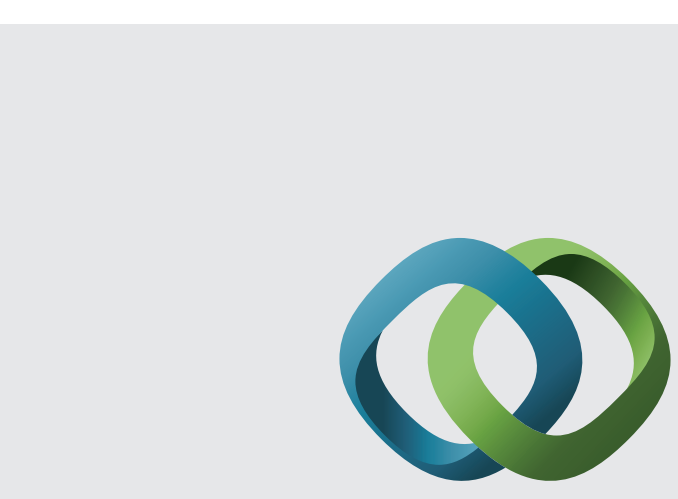

\section{Hindawi}

Submit your manuscripts at

http://www.hindawi.com
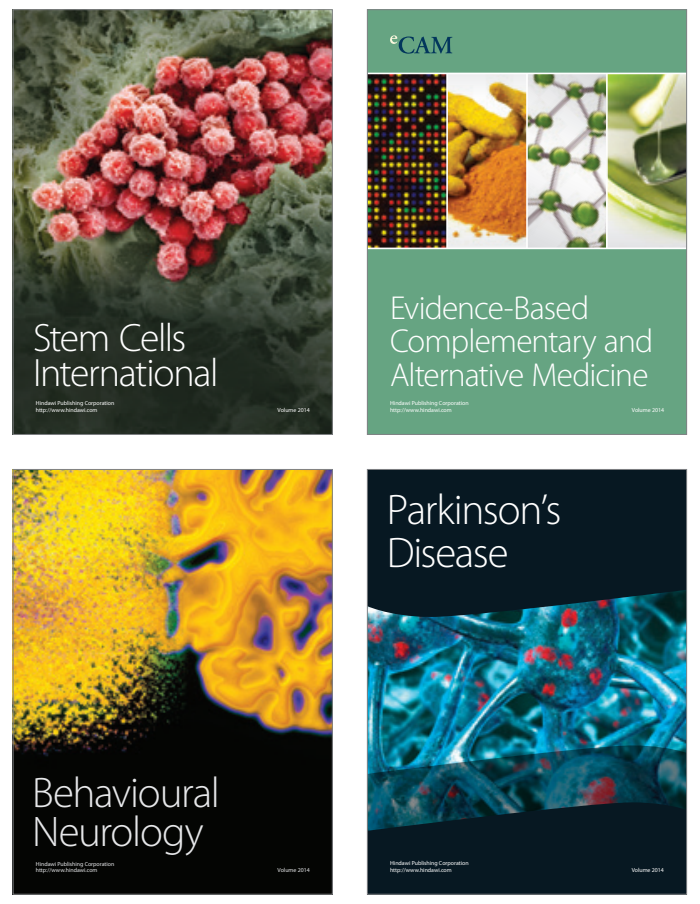
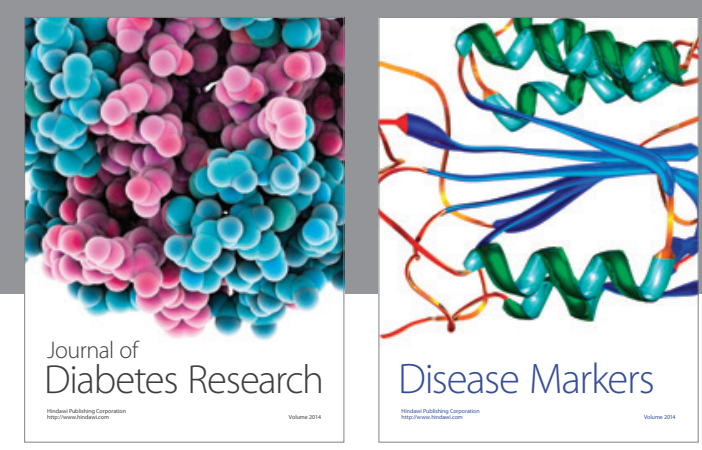

Disease Markers
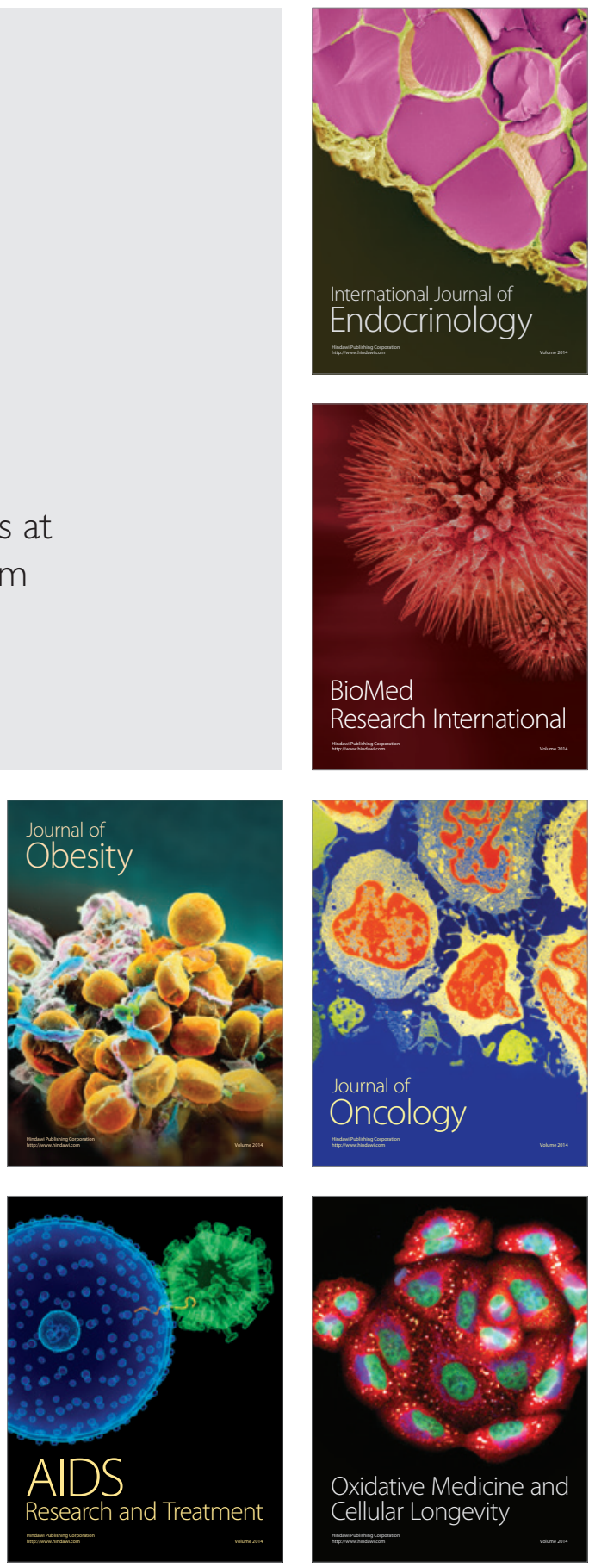